tendency for the disease to destroy life by the occurrence $/$ stomach is engaged in such a hernia. It is based upon of such complications as cerebral hæmorrhage and for the occurrence of uræmia. It is quite true that sometimes the sudden occurrence of uræmic symptoms suggests the onset of an acute complication, but still it is charactermaterial derived from 63 cases.

Diaphragmatic herniæ are of three kinds : (1) congenital ; (2) traumatic ; and (3) acquired.

1. Congenital.-Congenital cases are always due to istic for acute symptoms to arise in many chronic apertures in the diaphragm resulting from imperfect developdiseases and even to be fatal without the onset of any such ment. The nature of the diaphragm has been discussed by acute complication. This, for instance, is seen especially in diabetes and in hepatic cirrhosis. Acetonæmia in the one and cholæmia in the other, it would seem, may occur as a result of the progressive destruction of gland tissue. In these cases of contracted white kidney the urine at the time of the occurrence of the fatal uræmia does not present any changes that could be looked upon as indicative of acute nephritis. It is by no means uncommon for large quantities of urine to be excreted during the uræmic period, although perhaps it is more usual for the quantity to be diminished. The urine is not necessarily more albuminous during the terminal stages of the illness than at earlier periods. It would seem, therefore, from the study of the morbid anatomy, from the course of the clinical symptoms, and from the characters of the urine that the contracted white kidney is a distinct entity and not necessarily related to the large white kidney or the true granular kidney. One of the remaining problems is to consider the relationship, if any, existing between this form of Bright's disease and acute affections of the kidney, such as acute nephritis or acute Bright's disease. 'There can be no doubt that both acute nephritis and acute Bright's disease may occur in patients who subsequently may suffer from Bright's disease in one or other of its forms, and it would be rash to deny that the contracted white kidney may sometimes have that origin. It is, however, quite certain that it may occur in persons who have never suffered from dropsy and who have never been laid up by any serious illness and it is difficult to suppose that in all these cases acute nephritis has really been present at some antecedent period and has not been recognised. Not only may no history of acute nephritis or acute Bright's disease be obtained but sometimes no history of the acute specific diseases which are the more potent causes of the renal complications can be elicited and my own feeling is that not uncommonly this form of Bright's disease may arise independently and be slowly progressive and that it is not necessarily the sequel of an acute renal infection although it is very probable that in some instances it is.

\section{ON DIAPHRAGMATIC HERNIA OF THE STOMACH AND ON TORSION OF THE SMALL OMENTUM ANI) VOLVULUS OF THE STOMACH IN ASSO- CIATION WITH IT.}

BY R. LAWFORD KNAGGS, M.C., M.D. CANTAB., F.R.C.S. ENG.

SLRGEON TO THE LEEDS GENERAL INFIRMARY.

A GASTRIC hernia is usually diaphragmatic. It is exceedingly rare for the stomach to be found in any of the more usual forms of external hernia, if post-operative ventral protrusions occuring above the umbilicus be excepted. But hernia of the stomach constitutes a very considerable proportion of all cases of diaphragmatic hernia and the relations of the viscus to that structure are a sufficient explanation of its relative frequency. The object of the present paper is to consider the various conditions that are met with when the
FIG. 1.

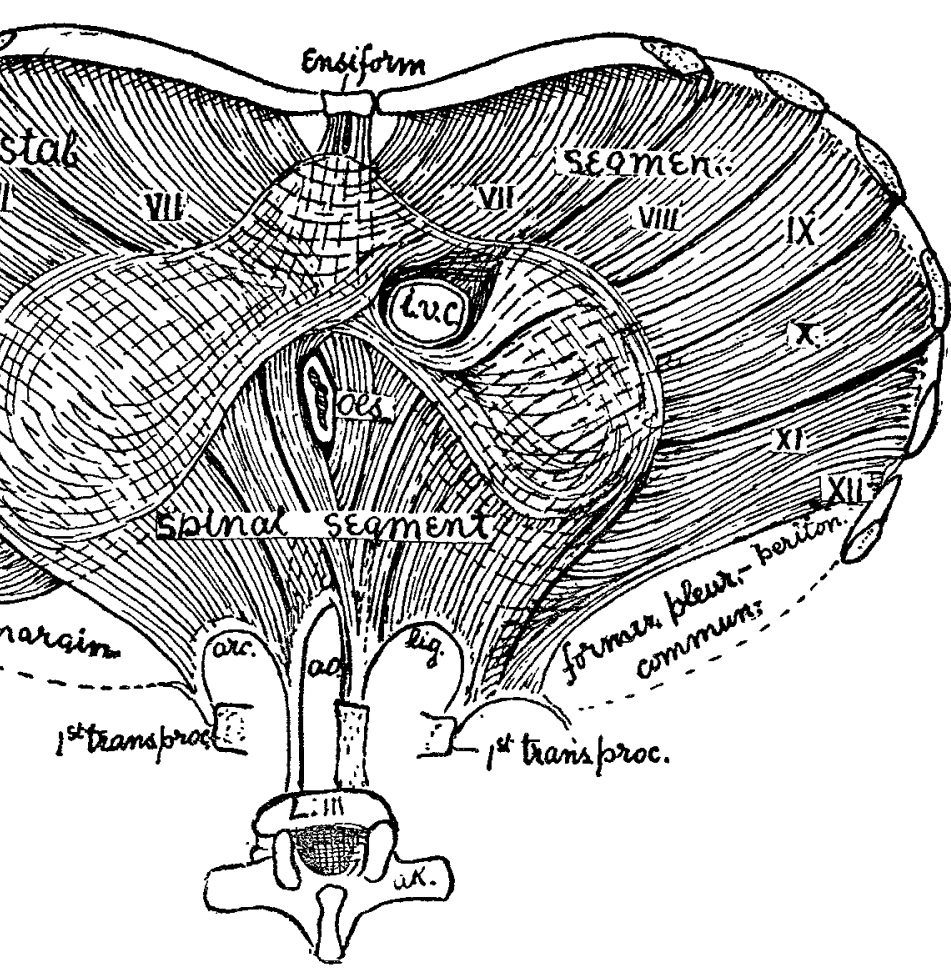

The diaphragm spread out and viewed on its thoracic aspect. Fibres pass through tal segment. (From THF. LAxcer of March 7th, 1903, p. 635.)
Dr. Arthur Keith in his recent Hunterian Lectures on Enteroptosis.* He points out that "in structure, in development in evolution, and in action the diaphragm is a true digastric muscle made up of two segments-a spinal or dorsal and a costal or ventral." In man with the assumption of the erect. posture the spinal segment spreads out laterally until the spinal and the costal segments almost meet (Fig. 1). In many subjects there is a fibrous interval between the origin and insertion of the diaphragm and this interval marks the site of the original communication between the pleural and peritoneal cavities and also the outer or lateral margin of the muscle. Dr. Keith states in THE LANCET of March 7th, 1903 , p. 635 , that "congenital diaphragmatic herniæ occur between this lateral margin of the diaphragm and the costal wall and in such cases the free lateral margin of the diaphragm can be seen very distinctly." No doubt this explanation is the correct one in many cases, for instance, in those-not infrequent-in which the diaphragm is stated to have been deficient or absent on the left side (see Fig. 2)

Fig. 2.

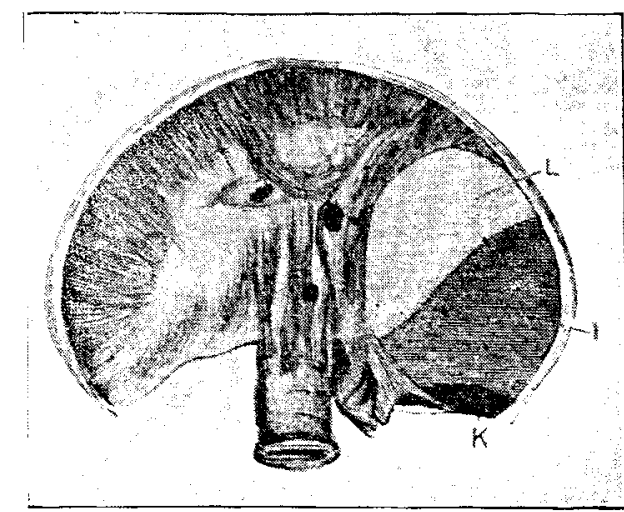

Large oval deficience on the left side of the diaphragm in a case of congenital clial hragmatic hernia. (From Dr. Thomas p. paver, Edimburgh yedicul Journal, vol xiv. p. 885.)

* The Laxcfet, March 7th and 14th, 1903. 
and in one ( $\left.{ }^{54}\right)$ in which there was a fissure between the central tenclon and the cartilages. But not every protrusion takes place external to the lateral margin. In one the anterior portion of the diaphragm behind the sternum and the cartilages was deficient and a gap existed bounded by a tense lunar arch $\left({ }^{48}\right)$. In other cases the aperture was in the tendon.

In stomach hernia the gap is in most cases on the left side but in three instances it was on the right and the presumption is, when it is not definitely stated, that the protrusion occurred into the right pleura $\left({ }^{38},{ }^{50},{ }^{58}\right)$. Of 24 congenital cases four were met with in foetuses, five in children who died at birth, and 15 in persons whose ages varied from six weeks to 60 years.

2. Traumatic.-Of 21 cases of stomach hernia following injury seven were due to wounds, seven to crushes, six to falls, and one to " being run over." The wounds were either stabs, sword or bullet injuries. Of the crushes two were "buffer accidents" and the falls were usually from a height. In every instance there was an aperture and this was more frequently situated in the tendinous than in the muscular part of the diaphragm and rarely near the origin of the muscular part from the ribs. In cases where the patients died soon after the injury the opening was of the nature of a tear or rent, but if the sufferer lived for some years it became a well-defined aperture, sometimes with rounded, smooth, and callous edges, and not infrequently there were adhesions in its neighbourhood between adjacent parts or the viscera engaged in it. The diaphragmatic wound was never fatal per se and the patient not infrequently survived unless there were associated injuries of a grave character.

3. Acquired. - The existence of a sac has been held by the writer to be conclusive evidence that the rupture has been acquired. Eight cases fulfil this requirement. Three found their way into the right chest $\left({ }^{6},{ }^{36},{ }^{63}\right)$ and four into the left $\left({ }^{29},{ }^{31},{ }^{32},{ }^{61}\right)$. The eighth case was the remarkable one recorded by Dr. Bright $\left({ }^{9}\right)$ in which a membranous sac bulged into both right and left chest (Fig. 3). It was

FIG. 3.

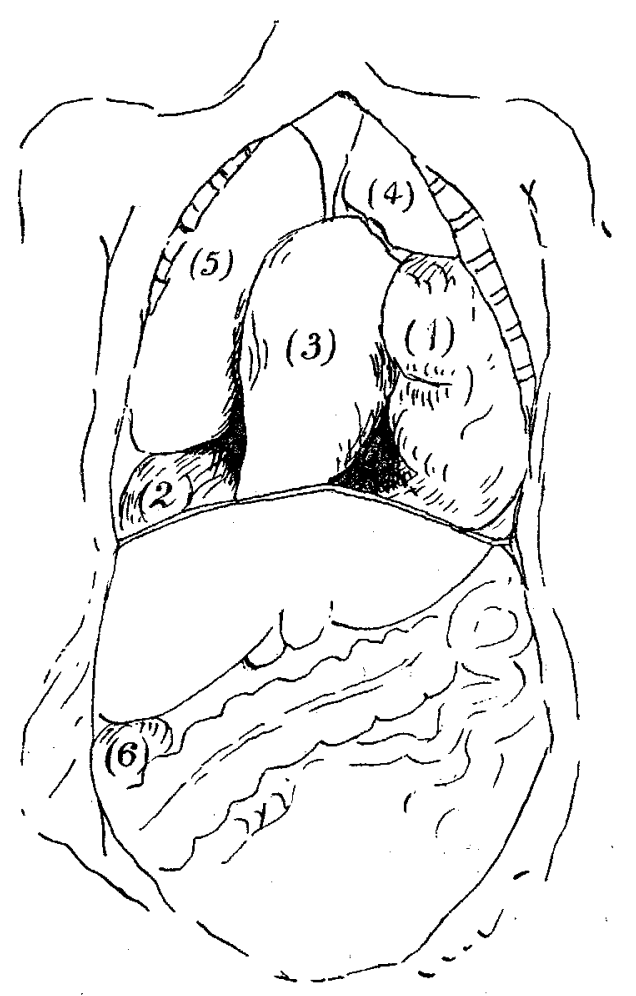

Diagram in connexion with Dr. Bright's case. 1, Larger portion of stomach. 2, Smaller portion of stomach. 3, Heart in the pericardium. 4, Left lung. 5, Right lung. 6, Distended pelvis of right kidney. (From Guy's Hospital Reports.)

thought to owe its origin to a congenital splitting of the diaphragm, but in the light of Dr. Keith's explanation of the development of the midriff this suggestion is almost certainly incorrect. Besides these there were two other cases $\left({ }^{34},{ }^{35}\right)$ in which no statement is made as to the existence of a sac, but since the hernia took place through a dilated osophageal opening in each case there is a strong presumption that both were acquired. In another instance $\left(^{44}\right)$ the hernia passed through a dilated cesophageal opening. Apparently there was no sac but the symptoms dated from a time when the patient "felt something rip in his inside" whilst lifting a pig of iron. Lastly, there is a form of hernia of the stomach through the cesophageal opening, of which Dr. Keith and Dr. Rigby have recorded an example. Here, owing to the descent of the diaphragm from the giving way of its supports, the cardiac orifice of the stomach comes to lie within the thorax and above the level of the muscle $\left({ }^{37}\right)$. (Fig. 4.) In all,

FIG. 4.

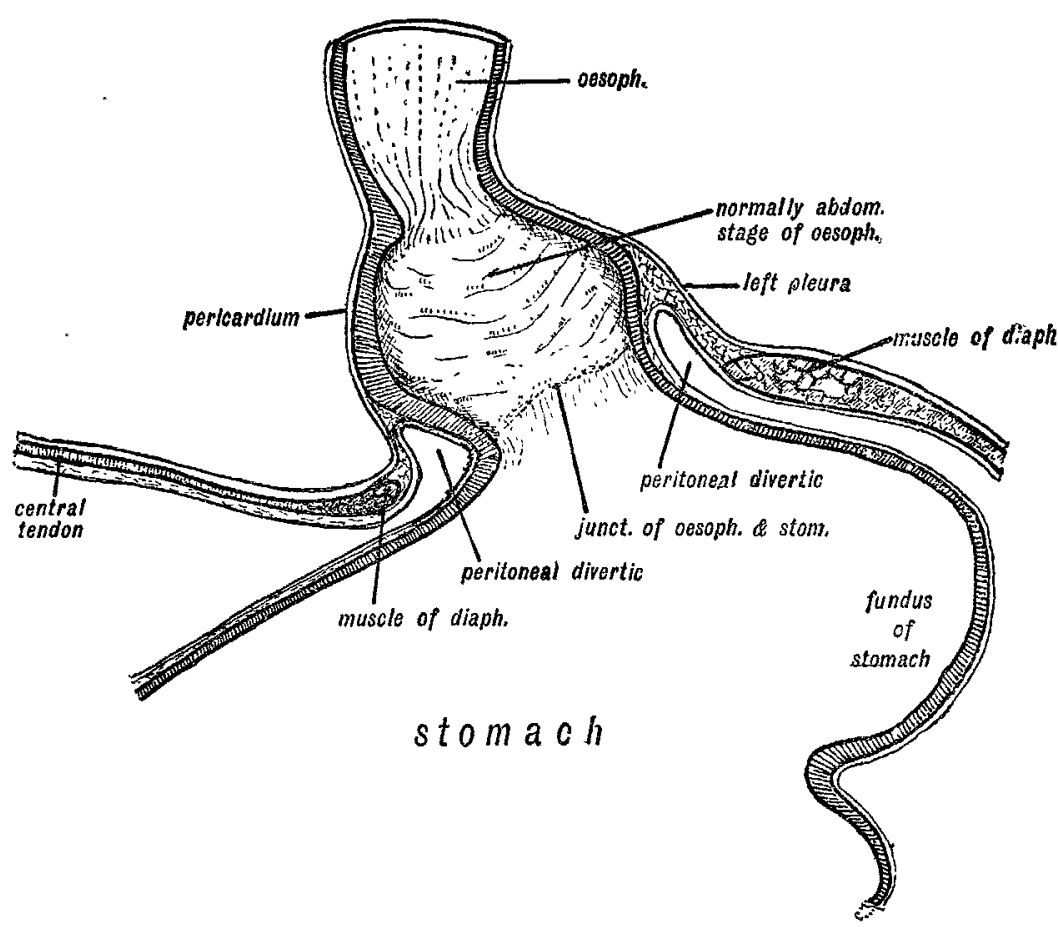

An example of diaphragmatic hernia of the stomach in a case of ptosis. (From the proceedings of the Anatomical Society of Great Britain and Ireland and published in The LAxCeT of March 7th, 1903.)

therefore, there were 12 cases of acquired hernia and it is of much interest to see how they were associated with certain natural weak places in the diaphragm. In no less than eight $\left({ }^{8},{ }^{81},{ }^{34},{ }^{35},{ }^{37},{ }^{44},{ }^{61},{ }^{63}\right)$ the protrusion was either through, or doubtiess determined by, the csophageal aperture.

Long ago Dr. T. Balfour pointed out that even when no hernia existed these natural foramina were occasionally found of unusual size. The osophageal foramen particularly seems to predispose to rupture and were it not that gravity exercises a contrary influence it would probably be met with oftener. Indeed, its more frequent occurrence in quadrupeds has been attributed by Sir Astley Cooper to the position of their bodies. There is also a weak spot on either side of the origin of the muscle from the ensiform cartilage, between that and the costal origins. This gap in the muscle (Fig. 1) is perforated by the superior epigastric branch of the internal mammary artery and in one case $\left({ }^{36}\right)$ the hernia followed this path. It may be added that hernix, though not of the stomach, have been known to take place through the opening transmitting the splanchnic nerve.

Hernia of the stomach may be (1) complete ; (2) incomplete; (3) partial or a Richter's hernia ; and (4) associated with other viscera.

1. The complete form.--Of this there is not mich to be said. The whole stomach has passed out of the abdomen into the sac or the thoracic cavity. With it there is certain to be more or less of the omentum and it may be a small portion of the duodenum. The greater curvature has in some cases been said to lie uppermost.

2. The incomplete form.--In incomplete hernia of the stomach the pyloric extremity is most frequently protruded, occasionally the cardiac end, and sometimes the middle portion of the viscus. The whole lumen, however, is engaged.

3. Partial or Richter's hernia of the stomach - Here the hernia is formed by a pouch-like projection of the stomach wall and does not include the whole lumen. Only two instances have been met with and in neither is there any clinical history. One is recorded by Dr. C. T. Andrew: "A dome-shaped pouch of the diaphragm existed immediately to the left of the osophageal opening and into it a portion of the cardiac end of the stomach, measuring vertically about an inch, was drawn. The hernia could easily be pulled down and the part of the stomach wall that lay against the neck of the pouch was thickened." The condition was found in the dissecting-room in a female subject and had probably caused 
no serious trouble during life $\left(^{31}\right)$. (Fig. 5.) The other is a specimen in the Guy's Hospital Museum, No. 1088. A pouch

FIG. 5.

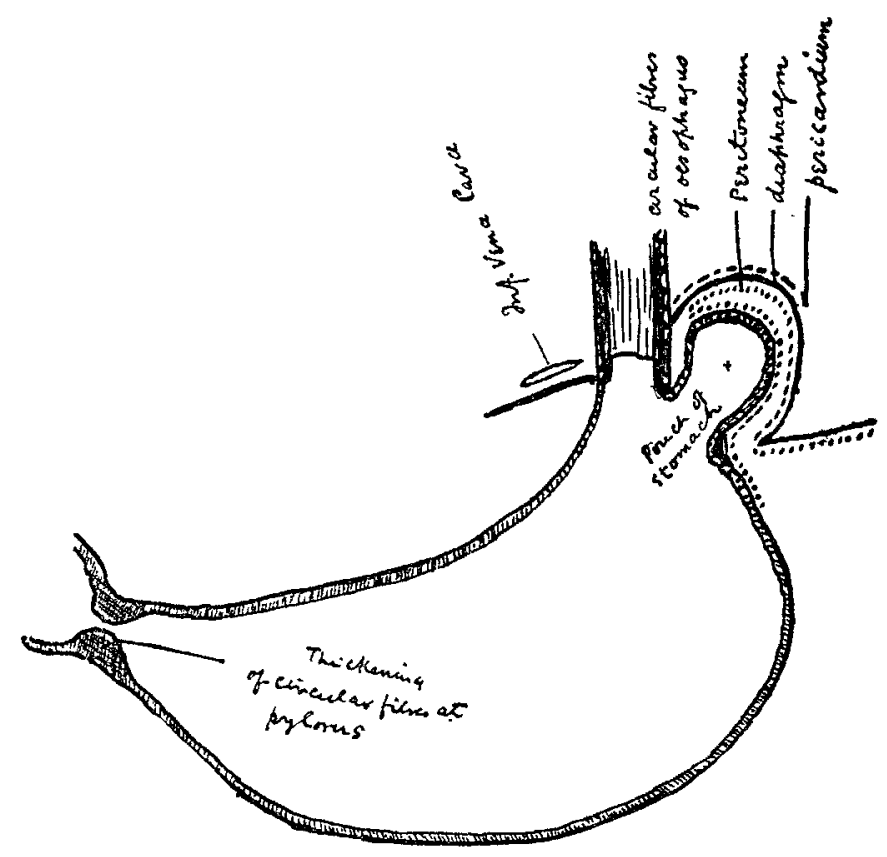

Stomach, showing diverticulum of cardiac end in the pouch of the diaphragm. (From THE LATCET of March 21st, 1903, p. 792.)

formed from the greater curvature has passed through an aperture in the diaphragm and has "evidently been strangled and the cause of death $\left({ }^{39}\right)$. (Fig. 6.)

Fig. 6.

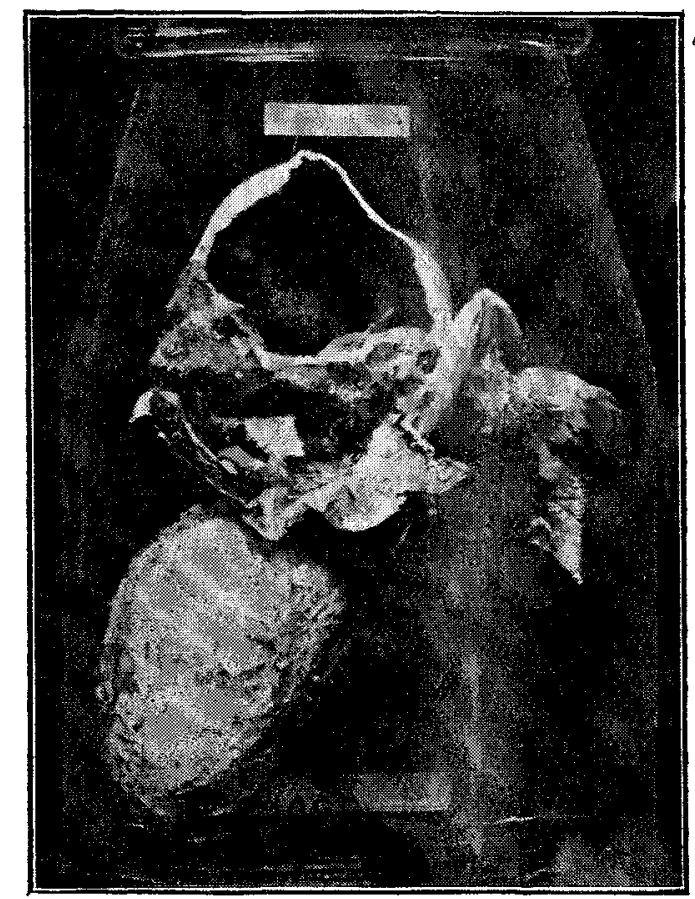

Guy's Hospital Museum, No. 1088. Diaphragmatic hernia. A portion of the diaphragm with the stomach and spleen mounted to show a smooth-edged perforation of the diaphragm, measuring about two inches in diameter, through which part of the stomarch and great omentum have passed into the thoracic cavity and become strangulated. Below the diaphragm the stomach is seen with its lesser curvature and its osophageal and pyloric orifices directed downwards.

\section{Diaphragmatic hernia in which the stomaeh is associated} with other viscera.

Table showing the Various Associated Viscera in the Hernice. 1. Stomach only

2. Stomach and part of duodenum

3. Stomach and omentum

4. Stomach and spleen

5. Stomach, spleen, pancreas, and colon

6. Stomach, spleen, and transverse colon

7. Stomach and colon

8. Stomach, liver, and small intestine

$\begin{array}{cccccc}\text { 8. Stomach, liver, and small intestine } & \ldots & \ldots & \ldots \\ \text { 9. Stomach. spleen, liver, omentum, and small } \\ \text { intestine (part) }\end{array}$

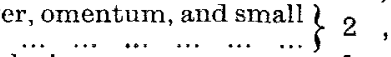

1 case.
Some interesting facts are brought out by this table. The colon, the spleen, the pancreas, and the liver are the viscera most likely to be found associated with a stomach hernia. The colon was met with 33 times, the spleen 16, and the pancreas five. The stomach was alone with the colon in 22 cases and alone with the spleen in three but the spleen and the colon were together in 11 . In every case in which the pancreas was found the spleen and part of the colon were also protruded. The frequent presence of the colon, spleen, and pancreas is not to be explained by their proximity to the aperture but to their close anatomical connexions with the stomach. Thus the colon follows the stomach because it is dragged after it by the gastro-colic omentum. The cardiac end of the stomach when it leaves the abdominal cavity pulls the spleen in its wake by the gastro-splenic omentum and the vessels and fascia which it incloses, and the pancreas follows owing to its connexions. with the splenic vessels and the subperitoneal fascia which accompanies the vessels into the different viscera. Consequently, as might be expected, the spleen is more frequently present than the pancreas, but the pancreas is never found without the spleen. The pancreas is the one abdominal viscus that has the credit of never having been found in a hernial sac. It may still continue to hold this record, for in all five instances it had passed through apertures or large gaps. The liver was present in all in seven cases. The gap is usually considerable when the liver is present, but though the close proximity of the liver to the gap cannot be overlooked yet it is probable that the traction exerted upon it by the gastro-hepatic omentum is a more determining cause. The presence of the small intestine, with the exception of the first part of the duodenum, is more accidental.

PREDisposing and Exciting Causes.

There is nothing to add to what has already been said about congenital apertures except that in one instance $\left({ }^{28}\right)$ the defective development was attributed to "maternal impression "in the early weeks of pregnancy. The causes of traumatic cases have also been considered. In the acquired the natural foramina are an obvious predisposing condition and muscular exertion is a frequent exciting cause. Thus in the case of a weakly child $\left(^{\circ}\right)$ a severe attack of vomiting lasting several days probably induced the rupture. In another ${ }^{(32}$ ) excruciating pain in the left hypochondrium came on during a violent effort to escape a blow and was followed by symptoms which ended in death. In a third $\left({ }^{41}\right)$ the patient was seized with a paroxysm of coughing whilst attempting to lift a pig of iron and felt something "rip in his inside." He died five days later from strangulation of the protruded viscera. In Dr. 'T. Churton's and the writer's case symptoms of stomach trouble became manifest a few months after a confinement $\left({ }^{63}\right)$. There is another case $\left({ }^{19}\right)$ in which the symptoms dated from a long and tedious confinement, but a few months before the patient had received a stab which most likely wounded the diaphragm. In the interval she had recovered from the injury and had enjoyed her usual health.

In one of the congenital cases, too $\left({ }^{15}\right)$, symptoms developed after a fit of crying and the infant, who had been in perfect health before, died in 24 hours. Lastly, there is the negative pressure within the thorax during inspiration to be taken into account. This is of most importance when a hernia has already formed and one of the lungs is more or less compressed and incapable of expansion. Under such conditions it would tend to prevent spontaneous reduction of a protrusion which might in many instances occur under the favouring influence of gravity. This influence must in diaphragmatic hernia be a powerful one, as a moment's consideration of the ease with which many inguinal and femoral herniæ disappear in the recumbent posture will show. Consequently some idea may be formed of the effect likely to be exerted by the thoracic aspiration.

\section{SYMPTOMS.}

In a condition in which not only the alimentary canal but the lungs and heart are likely to be incommoded seriously very varied symptoms may be anticipated. But various and irregular as they are, yet the majority fall naturally into one or more of the following groups: (1) dyspnoea; (2) dyspepsia; (3) obstruction and strangulation; and (4) tetany. In a few cases there were no symptoms referable

$\uparrow$ This does not appear from the table but in addition to the five cases mentioned there the liver was found in one of the spleen cases and in another where the spleen and pancreas were present. 
to the hernia $\left({ }^{24},{ }^{38},{ }^{40}\right)$ and one case at least was found unexpectedly (41).' 'Great thirst has several times been noted but there was always some serious complication in the shape of other injuries or a mortal consequence of the rupture $\left({ }^{1},{ }^{7},{ }^{2 \dagger},{ }^{26}\right)$.

1. Dyspnoea.-Respiratory difficulties are very common. They may be due to the pressure of the herniated viscera upon the heart or the lung. Sometimes one and sometimes the other may be chiefly answerable for the dyspnœa, but as in stomach hernia the left side is nearly always affected most likely both take a share. In one case in which the hernia was on the right side there was no complaint of difficulty of breathing. Difficult breathing in some instances is constant and may last for years. Sometimes there is a liability to sudden attacks at intervals. More often it is brought on by exercise or going upstairs, after a full meal or when food disagrees, though " the asthma" of one patient was relieved when he ate. In more than one case in which respiration was embarrassed there was lividity. In one $\left({ }^{2}\right)$ the face would become livid during the attack and in this and another the dyspnœa ended fatally $\left({ }^{52}\right)$.

2. Dyspepsia.-Where the hernia is chronic there is often a history of discomfort and vomiting after meals and sometimes of pain. These symptoms are probably induced by the difficulty in the propulsion of food from the stomach and are associated with dilatation of that viscus, often extreme, which is frequently described in the records of these cases.

3. Obstruction and strangulation.-The dyspeptic symptoms are only the earlier signs of obstruction which is incomplete and varying in degree, but they are very liable sooner or later to culminate in an acute attack of complete obstruction in which violent or excessive vomiting, often without retching, is accompanied by pain and constipation and terminates life in a few days. It is probable that in many of these cases a certain degree of strangulation is present and that they gradually merge into that class of case in which there is very definite interference with the circulation.

Lack of precision in description of the necropsies makes it impossible to form any real idea of the frequency with which strangulation occurs, but there can be no question that stranoulation was the cause of death in at least seven cases $\left({ }^{10},{ }^{18},{ }^{43},{ }^{44},{ }^{52},{ }^{61},{ }^{63}\right)$ and it is more than probable from the severity of the symptoms that it was present in six others.

4. Tetany.-In view of the attention that has been attracted of late to the association of tetany with gastric conditions the following brief report of a case under the late Sir Russell Reynolds $\left({ }^{19}\right)$ of diaphragmatic stomach hernia is of more than passing interest.

CASE 1.-A woman, aged 29 years, had been stabbed about the seventh rib on the left side some seven years before admission to University College Hospital. Though the lung was wounded she recovered good health. Then she had a long and tedious confinement and never recovered strength, suffering from repeated vomiting after taking food. This state of affairs had gone on for six years. She remained in hospital nearly five months without any great change. On March 29th she was flushed and uneasy. On the 30th contractions of the muscles of the forearms and arms were noticed. The hands were adducted, the fingers and forearms were flexed, resisting extension, and the patient could not move them. 'Then she became unable to open her mouth and had pain in the back and mouth. The temperature was $103.6^{\circ} \mathrm{F}$. In four hours from the commencement of the spasms she died in a state of general tonic spasm. At the post-mortem examination the whole of the stomach, with the exception of a small portion at the cardiac end, was found to be displaced together with several inches of the transverse colon and some omentum into the left thoracic cavity through an opening near the left edge of the central tendon of the diaphragm. The hernia was as large as two fists and had displaced the heart to the right. There was no tight constriction at the neck. There were adhesions both above and below the diaphragm.

\section{Physical Signs.}

The physical signs are very indeterminate. This is only what might be expected when it is remembered that a correct diagnosis has rarely been made before a post-mortem examination. Signs, indeed, are often marked but the difficulty lies in their interpretation. They may be divided into
(1) those of prime importance and (2) those of subsidiary value.

1. Signs of prime importance: (a) Stomach or intestinal noises in the chest. - The uncertainty in connexion with this sign lies in the possibility of the sounds being " transferred." Coupled with other signs, such as absence of respiratory murmur, it may be almost diagnostic and, indeed, it would appear that in some of the very few cases in which a diagnosis has been made during life it has been by the importance attached to them $\left({ }^{64}\right)$

(b) Intestinal peristalsis communicating writhing movements to the chest nall.--Such a sign would be of the utmost value if it were of frequent occurrence. It has, however, only been noted once (Holt) and in the case of a child $\left({ }^{46}\right)$. It is obvious that for it to occur the chest wall must be very supple and therefore it is only in the case of an infant that there would be a possibility of it being seen. It was due to the intestines in Holt's case, but there is no reason why stomach contractions should not be visible under similar suitable conditions.

(c) Displacement of the heart to the right side.-As a very large majority of all stomach herniæ occur into the left chest this is of frequent occurrence. It is, of course, only of value when joined to other signs.

(d) 1 respiratory bruit. In one case (Case 2, infra) there was heard over the left lower ribs in the posterior axillary line a peculiar blowing sound which was evidently connected with the respiratory movements. Had it been heard in the upper part of the chest it would have been described as "amphoric." One auscultator described it as "bubbling," but to most of the others who listened it was a "dry" sound. Its importance was not grasped at the time. It was not understood at all, but at the necropsy its explanation was obvious. It was produced by the forcing of gas during expiration from the herniated portion of the stomach into its abdominal portion through the narrow orifice caused by the constriction at the neck of the sac. It is hardly likely to occur with any other part of the alimentary canal than the stomach and with that only when a considerable portion lies in the thorax and another large portion in the abdomen. It implies the existence of a patent communication between the two portions at the neck of the sac and consequently the absence of strangulation by the neck is a fair inference. Its importance, therefore, when strangulation exists will be seen when volvulus of the stomach and torsion of the small omentum are discussed, for the latter of these conditions was present in the case in which it was heard.

2. Signs of subsidiary value.-(a) Absence of breath sounds; $(b)$ alterations in resonance; $(c)$ changes in shape and deficient movement of the side of the chest in which the hernia is situated; $(d)$ sinking in of the epigastrium ; and (e) inability to lie on the opposite side. Of most of these it may be affirmed that they vary in degree, are by no means constant, and are only of practical use as an aid of more or less value in the interpretation of some of the more important signs mentioned above.

\section{PATHOLOGY}

1. Adhesions.-Adhesions in the absence of strangulation are not very common. When they do occur they are usually omental and in the vicinity of the aperture.

2. Chronic ulcers. - In one case $\left(^{9}\right)$ in which the condition had existed for years there were two or three deep chronic ulcers.

3. Distension of the stomach.--This is often present and in some cases is enormous. Especially does it seem to have called for comment in those cases in which obstructive symptoms were present, but the latter were not necessarily associated.

4. Acoidental perforation.-Distension may lead to thinning of the stomach wall and has enabled a trivial accident to produce perforation and the extravasation of the copious contents into the pleural cavity. In the case in which this happened hæmorrhage was found to have taken place from a vessel which opened upon the perforation $\left({ }^{1}\right)$.

5. Strangulation and its consequences differ little from the same conditions elsewhere, but from the circumstance of the viscus protruding in many cases into the pleura that cavity may participate in the inflammation and a considerable pleuritic effusion may result.

The ulceration that occurs in strangulation of the stomach seems to be different from ulceration in strangulation of the intestine. In the latter it begins on the mucous surface and extends to the outer coats. In the case of the stomach 

the available evidence points to extreme distension pro-
ducing splits through the peritoneal and muscular coats, perforation being staved off for a time by the integrity of the sodden and rotten mucous membrane $\left({ }^{63}\right)$. Further, ulceration does not appear to have been noted at the seat of constriction, the most common place for it in the intestine.

6. Strangulation by volvulus of the stomach or by torsion of the small omentum.-There is one form of strangulation of the stomach met with in diaphragmatic hernia of that organ which presents unusual pathological peculiarities and which has not hitherto received any attention. It may be thought that strangulation of the stomach by volvulus is rather a far-fetched idea, but it uncloubtedly does occur and my attention was first directed to it by a case in which the post-mortem appearances were most unusual and their explanation apparently very difficult. Snbsequently he met with a case which had occurred at St. Bartholomew's Hospital in which presumably identical appearances had been found, and from a careful consideration of the two cases the conclusion was reached that both owed their peculiarities to twists by which certain vessels in the small omentum were affected and that the engagement of a portion of the stomach in a hernial orifice in the diaphragm was a feature essential to the condition. For permission to include the St. Bartholomew's Hospital case I am greatly indebted to $\mathrm{Mr}$. A. Willete under whose care the patient was admitted and to Mr. James Berry who made the post-mortem examination.

CASE 2. Diaphragmatic hernia of the stomach; torsion of the small omentum; strangulation; death.-A female, aged 29 years, was admitted into the Leeds General Infirmary under the care of Dr. Churton on Feb. 19th, 1901. Three months after a confinement and 18 months before admission she began to have dyspeptic symptoms. Later, vomiting after food set in and continued throughout another pregnancy which terminated without difficulty on Dec. 8th, 1900. Shortly afterwards streaks of blood occurred in the vomit and continued when the patient was not under treatment. On Dec. 15th she was poulticed for acute pain under the left shoulder. The patient was a pale and delicate looking woman and when admitted weighed 6 stones 11 pounds as against 8 stones 7 pounds two years before. Nothing abnormal was detected in the lungs. Both sides of the chest moved equally. There was a good entry of air. The percussion note was good and tactile vocal fremitus was normal. The heart's apex was felt in the fifth left interspace two and a quarter inches external to the middle line and the pulse was regular and 84. The bowels were dificult to regulate. Under a milk diet the vomiting ceased. On Feb. 21st she was allowed beef, potatoes, and rice pudding for dinner; indigestion followed and the pain became worse at 7 P.M. She vomited. At 10.30 P.M. she was much worse and collapsed, with cold hands, great pallor, and a very feeble pulse of 120 . Pain was felt in the epigastrium, the left hypochondrium, and across the body over the lower ribs. Liver dulness was uncertain. There was no marked abdominal distension but there was some rigidity over the epigastrium. Respirations were increased (27) and the entry of air into the left lower lobe was decidedly diminished. Over the last four or five lower ribs on the left side in the posterior axillary line an extraordinary sound like gas or air blowing into a cavity was heard during expiration. One observer described it as "bubbling." The patient was suspected to be suffering from gastric ulcer and the rapid development of these very acute symptoms was thought to point possibly to perforation. Under this impression I was asked to see the case with Dr. Churton and though the patient's condition was extremely bad it was felt that an operation should be performed. Ether was accordingly administered and transfusion was immediately commenced. The abdomen was opened by a median incision abore the umbilicus. The left lobe of the liver descended to within one and a half inches of the umbilicus. The stomach could not be seen. The colon was empty. The spleen and portion of the pancreas were easily brought into the wound. Inderneath the liver, where the stomach should have been, there lay a mass of omentum which could not be drawn away. Covered by this and placed deeply near the back of the liver a very tense, globular tumour was felt. It was fixed. On teasing through the omentum it was seen to be the stomach, tightly distencled, and of a bluish grey colour, and with several peritoneal lacerations of considerable size. The finger could be passed over a considerable portion of its surface without encountering any impediment. A stomach-tube was passed. The tumour disappeared at once and it was only by the presence of the tube that the whereabouts of the stomach could be detected beneath the omentum. Though there was a momentary improvement in the pulse on the relief of the distension the patient's condition rapidly began to fail and it became obvious that she could not bear the prolongation of an operation in which grave complications were certain. The abdomen was therefore closed. Five pints of saline solution had been injected into the median basilic vein. Death took place two hours later.

Necropsy. - When the body had been opened a large tumour was seen to exist in the right thorax in close contiguity with the pericardium. The tumour was the sac of a diaphragmatic hernia, was tightly distended, and as large as a very big cocoanut. It was surrounded by the lung which had been hollowed out like a cup by the tumour projecting into its base. This cup-shaped depression in the lung was the result of adaptation, not compression. Below the diaphragm and coming from behind the left lobe of the liver, which was tilted forward, was another tumour as large as that in the right thorax and tightly distended. This tumour, composed of the cardiac extremity of the stomach, was bluish in colour, deeply congested, and showed several large peritoneal cracks. The pylorus and first part of the duodenum were found on the right side of the tumour posteriorly and were quite normal in appearance. They could be traced to the diaphragm. The hernia was now reduced. The contents consisted of a small portion of the great omentum and the middle two-fifths of the stomach distended with fluid and gas. The portion that had lain within the sac was normal in colour and appearance. It was marked off from the pyloric portion, which remained in the abdomen, by a pale crease, but evidently there had been no interference with the circulation produced by the constriction of the neck of the sac.

On the other hand, there was a very sharp line of demarcation between the herniated portion and the cardiac ex tremity which had constituted the tumour in the abdomen. The latter showed marked signs of strangulation. Both surfaces of the fundus presented considerable peritoneal ruptures, which in some instances extended through the musculature and exposed the rotten mucous membrane. One of these perforated notwithstanding the care taken in the examination of the organ. On the internal surface of this portion of the stomach there was a hæmorrhagic erosion in addition to deep congestion and softening of the mucous

FIG. 7.

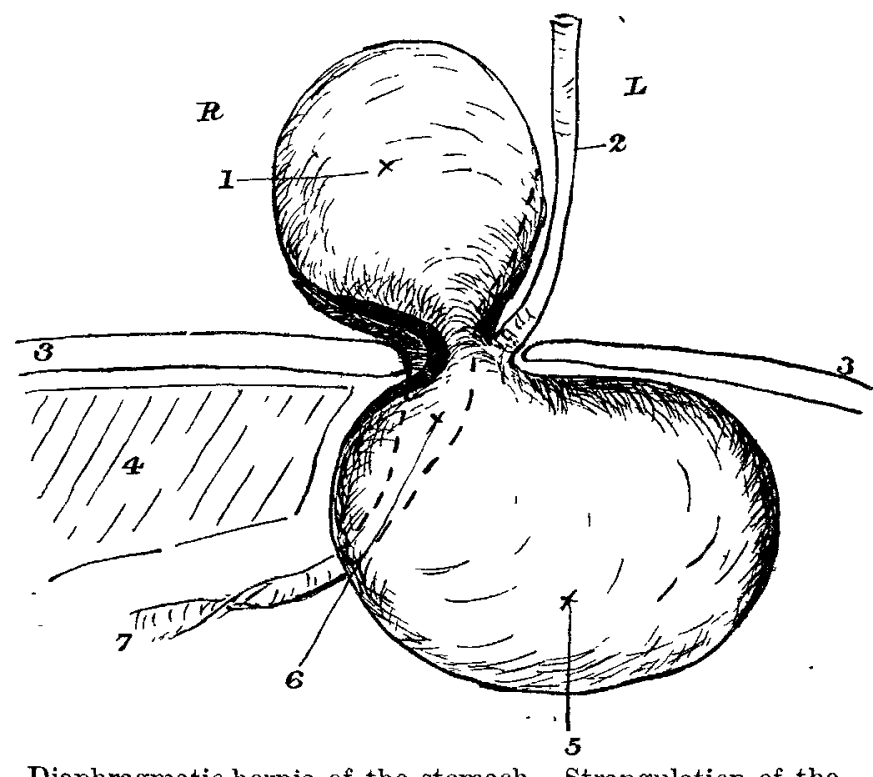

Diaphragmatic hernia of the stomach. Strangulation of the cardiac end from torsion of the small omentum. The hernial sac has been omitted. R, Right chest. L, Left chest. 1, Central portion of the stomach cuntained in hernial sac. 2, Esophagus. 3, Diaphragm. 4, liver. 5 , Cardiac end of the stomach.
stomach (concealed). 7 . Duodenum.

membrane. The mucous membrane of the herniated portion showed nothing abnormal. The protrusion had taken place through the csophageal opening and on the right of the gullet. It had passed behind the pericardium and, carrying before it the peritoneum continuous with the anterior surface of the gastro-hepatic omentum, it had received an additional covering from the right pleura. The sac was 
pedunculated and on its mediastinal side it had contracted an adhesion to the lung. Beyond the mobility of the spleen and pancreas no other abnormality of importance was found. (Fig. 7.)

OASE 3. Diaphragmatic hernia of the stomach; volvulus of the stomach; strangulation; death.-A man, aged 50 years, was admitted into St. Bartholomew's Hospital on Oct. 19th, 1897, under the care of $\mathrm{Mr}$. Willett, in a state of profound collapse and died on the stretcher as he entered the ward. $\mathrm{He}$ had suffered from severe abdominal pain and almost continuous vomiting for four days until relieved by morphine. When admitted he was quite conscious and the abdomen was distended in the upper half and not tender.

Necropsy. - The post-mortem examination was made by Mr. Berry. The left lung was much shrunken and occupied only the upper half of the left pleura. There were no adhesions. Bulging into the left side of the chest and covered by normal pleura was a large nearly globular sac measuring between four and five inches in diameter. It had a broad pedicle at the inner and lower part and was clearly a diaphragmatic hernia. "Abdomen.-The peritoneal cavity contained free gas. The lesser peritoneal carity was greatly distended and filled with a thin, nearly black, fluid looking like altered blood. This sac formed a huge globular mass

FIG. 8.

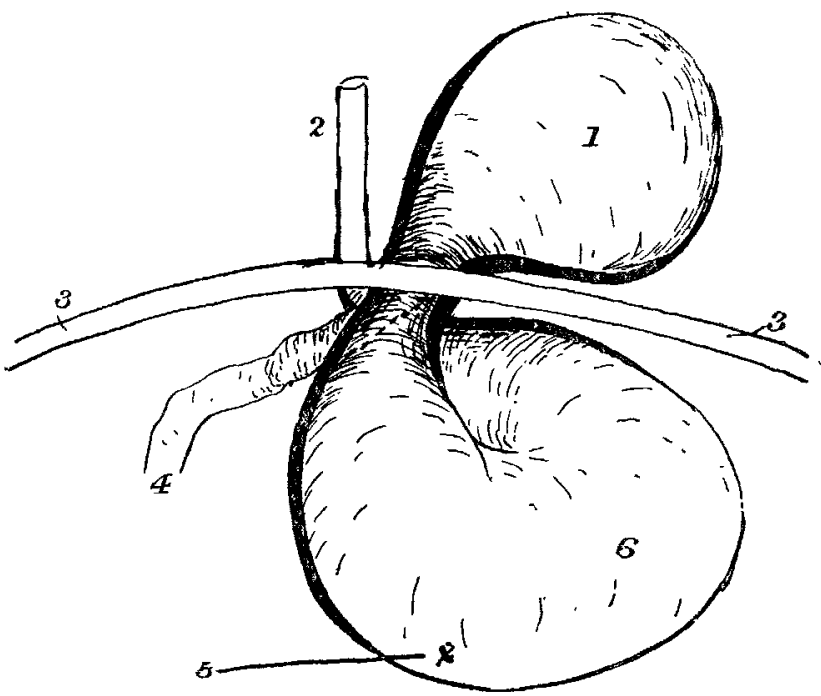

Diagram in connexion with Mr. Willett's case. Volvulus of the stomach. 1, Pyloric half of stomach in hernial sac. tion of (6) Cardiac end of stomach.

occupying most of the upper quadrant of the abdomen. The transverse colon ran across the lower part." "The stomach was remarkably abnormal in shape and position. About one-half of it-the cardiac end-was greatly distended, forming a rounded sac some six inches in diameter. This portion bulged into the lesser peritoneal sac above mentioned. At the lower border was a small perforation through which blackish fluid mixed with particles of food was oozing into the peritoneal cavity. A fairly well-marked and evidently old constriction separated this half of the stomach from the pyloric half which lay in the hernial sac. Nothing else but stomach lay in this sac and there was no inflammation, congestion, or other sign of strangulation. There was no fluid in the sac. When the pyloric half was drawn out of the sac the whole stomach was seen to be enormously dilated and the lesser omentum was greatly widened, being seven inches across at its widest part. A constriction at the pylorus marked the lower limit of that part that had been in the sac. The cardiac portion of the stomach was considerably decomposed and it was difficult to say whether the perforation was ante or post mortem. It seemed probable, however, that it had occurred a few hours before death on account of the large quantity of fluid distending the lesser peritoneal sac." "Diaphragm.-The opening in the diaphragm through which the hernia occurred was oval or nearly round and measured about two inches in diameter. It was situated just to the left of the oesophageal opening, the herniated portion of the stomach passing in front of the cesophageal end before entering the hernial sac. (Fig. 8.) The hernial opening appeared to have been congenital and the stomach had evidently been in the habit of passing freely into the sac for a long time. It was easily reduced by pulling and had probably often been spontaneously reduced. There was no sign of old injury to ribs, liver, diaphragm, or any other part." There was also a shrunken gall-bladder containing stones with some old adhesions around. There was no disease of any other abdominal viscus. (Note.I assume that the condition of the cardiac end of the stomach described in these notes was due to strangulation.)

There is one remarkable fact common to these cases that cannot fail to arrest attention-viz., that strangulation affected a part of the stomach which had not entered the hernial sac, whilst the hernial contents themselves were quite normal and uninjured. Indeed, there was no real difficulty experienced at the post-mortem examination in expressing those contents in the first case and in pulling them out in the second. Obviously the conditions were unusual. What is the explanation? The most important factor is torsion of the gastro-hepatic omentum from right to left through an angle of $180^{\circ}$. It only requires a glance at Figs. 7 and 8 to realise that the right-hand portion of the small omentum must be pulled very much out of its natural position and have its relation to the left-hand portion very much altered. As a matter of fact, it is pulled across it at right angles. The right-hand border, with the pylorus and duodenum attached, in its course to the aperture in the diaphragm lies superficial to the left-hand portion of the omentum and to the coronary artery and vein. In $\mathrm{Mr}$. Willett's case it passed in front of the cardiac end of the stomach and a true volvulus of the stomach was produced, but in Dr. Churton's and the writer's case, the hernial orifice being on the right side of the cesophagus and not on the left as in Mr. Willett's, this crossing of the stomach did not occur, but as will be readily understood the torsion of the omentum would be more pronounced.

Now the reason why only the cardiac portion of the stomach, situated outside the hernial sac, shows the effects of strangulation is because the circulation through the coronary artery and vein is interfered with. These vessels

FIG. 9

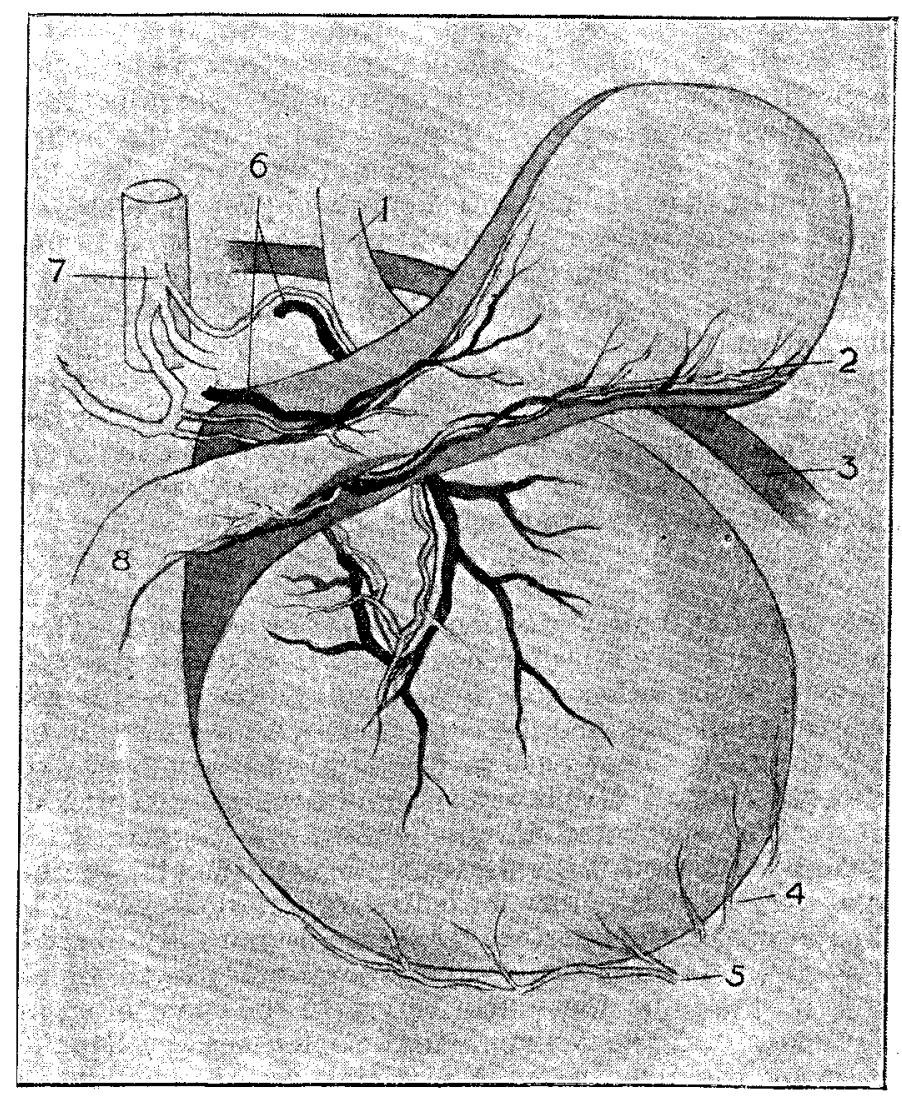

1, Esophagus. 2, Right gastro-epiploic artery. 3, Diaphragm. 4, Vasa brevia. 5, Left gastro-epiploic artery. 6, Coronar. and pyloric veins. 7 , Common trunk of splenie artery and hepatic artery, giving off pyloric artery and gast ro-d wodenal artery. 8, Duodenum. In this diagram the hernial sac has been omitted and the duodenum and pylorus have been represented as in front of the central portion of the stomach. But in the two cases ( 2 and 3 ) the position of the parts was reversed.

pass underneath the right-hand portion of the omentum and the pyloric portion of the stomach and which constitute a firm solid band of tissues fixed at either end-on one side at its engagement in the hernial orifice and on the other at the attachment of the lesser omentum to the transverse fissure of the liver. The arrangement of the parts is diagrammatically represented in Fig. 9. When in these circumstances, the 
pyloric portion being inclosed within a sac, the stomiach becomes distended the cardiac extremity is more at liberty to expand than any other part of the organ. As it does so it must come forward and the coronary vessels get bent or wrapped round the posterior and lower surface of the stretched and taut overlying structures. The gradual interference with the circulation through the coronary vessels produced in this way speedily gives rise to further distension of the stomach generally and of the fundus in particular and the strangulation rapidly increases. But all this time the circulation to the pylorus and the portion of the stomach occupying the hernial sac is maintained by the pyloric and the right gastro-epiploic vessels which lying in the compressing and not the compressed structures are not really incommoded. It is quite possible that with increasing distension consequent upon strangulation of the fundus produced in this way the hernial contents might gradually develop so tight a constriction at the neck of the sac as to induce strangulation of the herniated portion of the stomach, but this would be a purely secondary strangulation and was not observed in either of these cases.

The writer has elsewhere drawn attention to the manner in which herniæ in other regions are sometimes associated with intra-abdominal volvulus. The present condition is only a precisely similar state of affairs, but owing to the peculiarities of the organ affected the pathological consequences are more striking and not so readily understood. The principles are, however, the same $\left({ }^{65}\right)$.

\section{Cause of Death.}

of the cases of diaphragmatic hernia from which this paper is compiled a fair proportion of the cases (about 1 in 8 ) died from conditions which apparently had no connexion whatever with the hernia. A similar proportion of cases died in utero or at birth or lived with difficulty for a few hours. There can be no doubt that the abnormality, which in many of these cases was extreme, was responsible for their feeble vitality. No less than a fourth of all the patients died as a direct result of obstruction or strangulation and the complications directly resulting from it. Three patients died in alarming attacks of dyspnoea and in all the hernia was on the left side. Though not definitely stated, there can be little doubt that the pressure upon, and displacement of, the heart must have been the most important element in producing it $\left({ }^{2},{ }^{15},{ }^{33}\right)$. One patient died from perforation of a thinned portion of the stomach wall ( $\left.{ }^{l}\right)$ and another from tetanoid spasm $\left({ }^{19}\right)$.

Finally, in about one-eighth of the cases the hernia was accompanied by other serious injuries and it would be impossible in the majority of them to attribute death to the hernia alone, though in two $\left({ }^{20},{ }^{47}\right)$ it may certainly be affirmed that death was independent of it.

\section{TREATMENT.}

This does not call for much remark at present. These cases have very rarely been recognised before death and I am only aware of one other case of stomach hernia besides that under Dr. Churton's and my care in which an operation has been performed. That case is briefly recorded below by the kind permission of Mr. Berry, as an instance in which the condition was suspected. if not definitely diagnosed, before operation. Further, it illustrates the great difficulty there is in carrying out satisfactory measures for a radical cure.

The closure of the aperture by suture is not only likely to be very troublesome but in many cases probably impossiblethat is, if it is to be done effectively. In the event of suture being unavailing the aperture may sometimes, perhaps, be covered by the liver, as in Mr. Berry's case. Though the liver would gradually mould itself to the opening and protrude through it, yet such protrusion, if it filled the gap and prevented the hollow viscera entering, would be of great value and but little, if any, inconvenience. Another plan that might be tried would be the anchoring of the stomach and the omentum to the parietes in such a way as to prevent other abdominal contents finding their way into the opening.

CASE 4. Traumatic gastric hernia; operation: death.-A two trucks on Nov. 11th, 1898, and was admitted to the Royal Free Hospital under the care of Mr. Berry. He was collapsed on admission and there was superficial evidence of injury over the upper part of the abdomen, in the loin, and over the lower ribs. No air could be heard in the chest below the third rib on the left side and the left side was dull behind the mid-axillary line. Very marked pallor was a prominent symptom. There were much sickness (beginning on the third day), the vomit being coffee coloured, great thirst, and not much pain. On Nov. 15th the heart was evidently displaced to the right side, and a tympanitic resonance extended over the front of the left chest almost to the clavicle and blended below with the abdominal resonance. A bruit d'airain was heard over the tympanitic area. The breath sounds were normal over the right lung. The diagnosis lay between pneumothorax and gastric hernia.

As the patient got worse Mr. Berry operated at midnight on Nov. 16th. On opening the abdomen a large hole was felt in the diaphragm, through which about half the stomach, the transverse colon, the duodenum, half the spleen, and the upper half of the left kidney had passed into the thorax. With difficulty the parts were reduced, the stomach being enormously distended and tightly grasped, and the spleen being in two distinct halves, one in the thorax and the other in the abdomen. The hole was as large as a man's fist and was situated at the back of the diaphragm between it and the left last rib. It was very difficult to sew up, so by a couple of stitches in the liver that organ served to plug up the hole. The patient died at the close of the operation.

References: (Nos. 1 to 63 inclusive refer to individual cases.) 1 Alderson: THE LAxcer, Oct. 16th, 1858, p. 396. 2 Beck: Transactions of the Pathological Society of London, vol. vi., p. 219 . J Johnson: Medico-Chirurgical Review, vol. x., p. 600,1827 . 4 Hunt: Quoted by Medico-Chirurgical Review, vol. x., p. 600, 1827. 4 Hunt: Quoted by
Johnson, ibid., p. 599. 5 Peacock: Transactions of the Pathological Johnson, ibid., p. 599. 5 Peacock : Transactions of the Pathological
Society of London, vol. xiv., p. 146, 1863. 6 G. Garlick: Ibid., vol. Society of London, rol. xiv., p. 146, 1863. 6 G. Garlick: Ibid., vol.
xxix., p. 125, 1878. 7 J. H. Targett, Ibid., vol. xxxvii., p. 239, 1886. 8 Morgagni : Oph. Nat. Cur., book iv., Section 54 (quoted in Balfour's paper in Edinburgh Medical Journal, vol. xir.) 9 Bright: Guy's Hospital Reports, vol. i., No. 3., p. 598 . 10 R. Macnab: THE LANCET, Jan. 5th, 1878, p. 11. ${ }^{11} \mathrm{H}$. W. Randolph : Brit. Med. Jour., vol. ii.,
1873 , p. 514 . 12 Mentioned by Norris : Transactions of the Prov. M.S. Assoc., vol. v., p. 345.13 Reid: Edinburgh Medical and Surgical Journal, vol. liv., p. 112, 1840. 14 Traill : Quoted by Reid, ibid., p. 114. 15 Sym: Quoted by Balfour; also ibid., vol. xxvi., p. 293, 1826. 16 Bartholin and Clauder: Quoted by (1) Reid, ibid., vol. liii., p. 107; and (2) Balfour, Edinburgh Medical Journal, rol. xiv., p. 894. 17 Chauvet: Quoted by (1) Reid, Edinburgh Medical and Surgical p. 895. 18 Macfadyen : Eidinburgh Medical and Surgical Journal, vol. xix.. p. 382, 1823 . 19 Russell Reynolds : THE LAxcET, August 3rd, 1872, p. 151 . 20 A.S. Taylor: Guy's Hospital Reports, series i., vol. iii., p. 366. 21 Dessault: Quoted by Reid, Edinburgh Medical and Surgical Journal, rol. liii., p. 112, 1840, 22 McCrie : Quoted by Reirl, ibid. 23 Sennertus

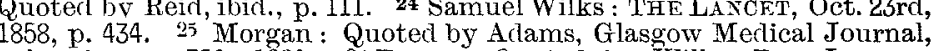
1858, p. 434. 25 Morgan: Quoted by Adams, Glasgow Medical Journal,

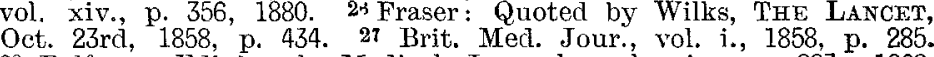
Oct. 23rd, 1858, p. 434. 27 Brit. Med. Jour., rol. i., 1858, p. 285.
28 Balfour : Erlinburgh Mertical Journal, vol. xiv., p. 883, 1869. 2* Petit: Quoted by Balfour, ibid., p. 893 . 30 Petit: Quoted by (1) Reid, Edinburgh Medical and Surgical Journal, vol. liii., p. 108 ; (2) Balfour. Edinburgh Medical and Surgical Journal, vol. liii., p. 108 ; (2) Balfour. C. T. Andrew : THF LANCET, May 21st, 1903, p. 792. 32 Laurence : Quoted by Balfour, Edinburgh Medical dournal, vol. xiv., p. 894 . (quoter by Balfour). 35 Schoberus : Quoted by Balfour. 36 Bowles : Quoted by Balfour). 35 Schoberus: Quoted by Balfour. 36 Bowles : Quoted by (1) Sir Astley Cooper; (2) Reid, Edinburgh Medical and Surgical Journal, vol. liii.; and (3) Balfour. 37 Keith and Rigby : 1903 , p. 639 ; Proceedings of the Anatomical Society of Great Britain and Ireland, November, 1901. 33 Riverius: Quoted by (1) Reid, Edinburgh Medical and Surgical Journal, vol. liii., p. 107; and (2) Balfour. "y Guy's Hospital Museum Catalogue, vol. i., p. 396, No. 1088. 40 Becker : Quoted by Morgagni, Balfour's paper. p. 905. 42 Guthrie. Qu Balfour, Edinburgh Medical Journal, vol. xiv, Dec. 6th, 1856, p. 1034. 43 Guthrie : Quoted by Duncalfe, ibid., p. 1038. 4t Duncalfe: Ibid., p. 1034. 45 Kendall : Medical Times and Gazette, March 11th, 1865, p. 253. 46 Balfour: Edinburgh Medical Journal, vol. xiv., 1869, p. 895. 47 Derrecagaix: Quoted vol Peacock, Transactions of the Pathological Socify our, Edinburgh Medical Journal, vol xiv $p .895$ 4y Paterson. Quoted by Balfour, ibic., p. 896. 50 Martin St. Ange: Quoted by Balfour, ibid., p. 897. ${ }_{51}$ D. H. Luschk: Quoted by Balfour, ibid., p. 898. 52 Copeman : Quoted by Balfour, ibid., p. 900 . 53 Balfour: Ibid. (Case 26). 54 Haller : Quoted by Balfour, ibid., p. 895 . 55 Chaussier: Quoted by Balfour, ibid., p. 896. 56 I' Aulay : Quoted by Balfour, ibid. 57 Lobstein Quoted by Balfour, ibid., p. 898 (Case 15) 58 Baron: Quoted by Balfour, ibid., p. 898. 59 Crang: Quoted by Balfour, ibid., p. 899 60 Robinson : Quoted by Balfour, ibid., p. 901.61 Willett: Vide present paper. 62 Berry : Vide present paper. 63 Churton and Knaggs : Vide present paper. 64 Bowditch : Association
1856.65 Annals of Surgery, April, 1900.

Leeds.

Gloucester General Infirmary.-The nurses' home, which has been erected in the grounds of the Gloucester Infirmary, was formally opened by Sir Michael Hicks Beach on July 23rd. The building, which has been erected at a cost of $\$ 7200$, constitutes the main portion of a scheme involving an expenditure of about $£ 10,600$ for bringing the infirmary up to modern requirements. $£ 7500$ have been already received for the purpose and Sir Michael HicksBeach made a strong appeal for the $£ 3100$ still required. 


\section{HEART LESIONS : SOME POINTS IN THEIR DIAGNOSIS AND TREATMENT.}

By JOHN HILL ABRAM, M.D. LOND.,

PHYSICIAN TO THE ROYAL INFIRMARY, LIVERPOOL; LECTURER AND EXAMINER IN CLINICAL MEDICINE, UNIVERSIIY OF LIVFRPOOL.

From the time of my promotion to the senior staff of the Royal Infirmary 81 cases of heart trouble have come under my observation. Two cases were admitted moribund and no post-mortem examination was obtained in either case. There were four examples of congenital disease; no points of novelty were noted. Mitral lesions were present in 39 cases; 13 presented the signs of stenosis in addition to those of regurgitation, and five, moreover, had definite evidence of adherent pericardium. In 31 out of the 39 cases there was a definite history of rheumatism. In this group three deaths occurred, two cases of regurgitation, aged 50 and 56 years, and one of stenosis, aged 21 years. Aortic regurgitation was found in seven cases; three of these were under 30 years of age and had a definite history of rheumatism; the remaining four were over 30 years of age, two had suffered from syphilis, and two showed marked vascular degeneration. There was one death in this group, a young woman, aged 29 years, who died suddenly; a post-mortem examination was refused. Combined aortic and mitral lesions were found in eight cases; four gave a history of rheumatism and four evidence of general vascular disease. The vascular cases were all in males over 40 years of age. There were two deaths in this group. The renal cardiac cases embraced 16 admitted with cardiac symptoms due to chronic renal disease. Six of these had on admission and discharge a mitral regurgitant murmur; three cases had a mitral systolic murmur on admission which disappeared and two had an aortic diastolic murmur on admission which disappeared. Four deaths took place in this group all over 45 years of age. Five cases of infective endocarditis came under notice; all died and were confirmed by post-mortem examination. In one of these the rise in temperature occurred irregularly and was only detected by taking the temperature every two hours, an important point. In another stenosis of the pulmonary valve was found, the infective lesion being a patch of acute vegetative disease of the pulmonary artery proximal to the bifurcation. This last case apparently followed an attack of pneumonia, but the infective lesion was streptococcal in nature (organisms were cultivated from the blood during life). In this group all the cases succumbed. In this rapid résumé the preponderance of mitral cases, nearly half the number, and the importance of rheumatism in their causation stand out prominently. These cases offer a wide field for discussion and if I must content myself with noting only a few points the limitation is made with good reason.

The possessor of a heart lesion may be absolutely unconscious thereof; on the other hand, he may present many symptoms which can usefully be classed as direct and indirect. In the former group we find various subjective sensations-palpitation, dyspnoea, and alterations in the cardiac rhythm; in the latter symptoms which for the most part are attributable to passive congestion of the various organs-lungs, liver, kidney, or brain. Yet another source, embolism, may give rise to symptoms far removed apparently from the primary lesion. It is unnecessary for me to detail the various symptoms but I shall touch upon a few to emphasise the difficulty which we shall often meet in our work.

Let us consider for a moment the subjective sensations that may be present. As you all know, they vary from the merest præcordial discomfort to the agony of angina pectoris. I should say that given a heart lesion the severity of the subjective trouble bears often absolutely no relation to the gravity of the lesion. The fatal case of aortic disease was attended with practically no pain at all. But a still more important point is this, even severe anginal pain causing collapse may occur without there being any actual hear lesion at all. These cases are not seen in my experience in hospital practice, they occur in better-class subjects, often neurotics, who are overworked, either mentally or physically. Close inquiry often elicits a history of irregular

1 A paper read before the St. Helens Medical Society. feeding and possibly excess in alcohol and tobacco, especially the latter. Rest, careful dieting, and a holiday work wonders. We are all familiar with the abnormal sensations in the chest due to gastro-intestinal disturbance and $I$ have a vivid recollection of a patient in the ward of the late Dr. A. Davidson whose "mediastinal tumour" was removed by a few doses of Gregory's powder. A much more serious difficulty I can illustrate with a case.

CASE 1.-A man, aged 48 years, was sent to me for severe anginal attacks. His medical adviser failed to find any condition to explain them. I in my turn found the heart and vascular system quite healthy. The man was kept under observation and eventually definite evidence of nerveroot implication was obtained and finally the case was cleared up by the appearance of cedema of the left arm. A necropsy showed a malignant growth starting from the upper dorsal vertebræ.

Palpitation is another symptom which may be considered for a moment or two. Perhaps of all heart symptoms it is most often unaccompanied by heart lesions. Anyone conscious of his heart's action may be said to have palpitation; the heart's action may be unaltered or may be irregular. In either case careful attention must be paid to the apparent exciting cause. When due to severe exertion it is a physiological phenomenon, but when it appears with slight exertion some underlying state can usually be detected, such as neurosis, chlorosis, or heart trouble. It may also appear, apart from exertion, after the intake of food or emotional disturbance, and its association with gastric disturbance is well known. By far the most frequent variety is the nervous one, with a weak nervous system, whether inherited or acquired. Palpitation appears under the strain of the body changes at puberty and the menopause, or under physical or mental overwork. Similarly many cases of tea and tobacco palpitation have a nervous basis.

Is nervous palpitation due to sympathetic stimulation or vagus inhibition? In many cases it is impossible to say. In some, however, the associated vascular changes justify the implication of the former. Two cases will illustrate this.

CASE 2.-A young male neurasthenic came to the infirmary suffering from palpitation which I found to be associated with marked pulsation in the vessels, notably the abdominal aorta. This condition has been termed by Dana pulsating neurasthenia.

CASE 3.--In private I saw a young male adult who with severe attacks of palpitation had marked tachycardia and wasting. 'Three months' rest produced a complete recovery which has been maintained for over three years.

I always teach that the symptoms of chest mischief may be due to lesions of practically any of the thoracic organs, but it is also important to note that chest lesions may give rise to symptoms pointing elsewhere. I may be allowed to give some examples not limited to heart cases. Some years ago I collected a series of cases of pneumonia and found that one-third of the number began with vomiting. I should add that my cases were all adults. A striking case was in my ward last year.

CASE 4.--A man, aged 44 years, was admitted for cough and pain in the chest. He had suffered from a septic finger. The temperature was a septic one, a well-marked leucocytosis was present, and he had signs pointing to effusion in the left chest, deficient movement, absent vocal fremitus, dulness, and feeble bronchial breathing. A needle drew pus but operation found the pleural cavity obliterated. A necropsy a week later revealed a suppurating bronchopneumonia secondary to an aneurysm pressing upon the left bronchus.

An important case with a direct bearing upon the point I wish to make is the following.

CASE 5.-A woman, aged 46 years, was sent to me with a history of hæmoptysis and some wasting. Her medical adviser had found evidence of consolidation at the apices. I corroborated his finding but discovered further that she had very definite mitral stenosis. No tubercle bacilli were found in the sputum and the further history has shown the lung lesion to be secondary to the heart state.

CASE 6.-Another case I well remember was sent for examination purposes some years ago as one of aortic aneurysm. I am happy to say that our Liverpool students who saw it recognised it as a case of fibroid contracting lung exposing a normal vessel.

A final case in this connexion

CASE 7.-A woman, aged 27 years, was sent to my 